\title{
Stock Market Price and the Performance of the Residential Property Market in Kenya
}

\author{
Charles Njoroge* Willy Muturi Oluoch Oluoch \\ School of Business, Jomo Kenyatta University of Agriculture and Technology, PO Box 62000 - 00200 Nairobi, \\ Kenya
}

\begin{abstract}
The purpose of the study was to assess the effect of stock market price on the performance of the residential property market in Kenya. The surge of the residential property prices in Kenya has ignited concerns about the affordability of residential property houses in Kenya. The escalation of residential property prices raises question as to whether it is in tandem with other markets in the Country especially the stock market. Researchers have inconclusive findings on the direction of causation or the strength of the relationship between stock market and performance of residential property market in Kenya. This study adopted a positivist philosophical attitude using causal research design. The study used quarterly secondary data from 2005 to 2018 . The study employed vector error correction residual serial correlation langrange multiplier test and vector error residual heteroskedasticity test as the diagnostic tests. Vector error correction model and auto-regressive distributed lag model were employed to test the hypothesis in the short run and long run respectively. The study found that stock market price had a negative effect on performance of residential property market in Kenya in the short term suggesting substitution effect while in the long run stock market price had a positive effect on the performance of residential property market in line with the wealth effect. The study concludes that stock market information spills over and affects residential property market performance in Kenya both in the long run and short run. The study has also contributed to the confounding empirical and theoretical literature and narrowed the research gap especially on the conflicting substitution effect and wealth effect of stock market and residential property market performance in Kenya.
\end{abstract}

Keywords: Stock Market Price, Performance, Residential Property Market

DOI: $10.7176 / \mathrm{RJFA} / 10-18-15$

Publication date:September $30^{\text {th }} 2019$

\section{Introduction}

The theoretical framework was confounding as to whether wealth effect or substitution effect explains the relationship between stock market price and performance of residential property market. Similarly the empirical literature was conflicting. Wokker and Swieringa (2016) did a study on foreign investment and residential property price growth. Their study used fixed effects panel regression techniques to estimate the impact of foreign demand for Australian residential real estate on property prices. According to Wokker and Swieringa (2016) stock market returns may affect the demand for properties as some people view them as substitute investments. If investors use past performance as an indicator of an asset class's future performance then a fall in stock returns would decrease expected future returns and thereby reduce the attractiveness of stocks in comparison to residential property market. This would imply a negative correlation between stock market and property returns.

Glindro et al. (2011) investigated the characteristics of house price dynamics and the role of institutional factor in nine Asia-Pacific economies during 1993-2006. They used trend series of mortgage credit-to-GDP ratios and the equity prices in examining the determination of house price fundamentals. They observed that on average house prices tend to be more volatile in markets with lower supply elasticity and a more flexible business environment. They also observed that equity prices were negatively related to house prices, suggesting that the substitution effect dominates the wealth effect during the study period.

Pillaiyan (2015) investigated the macroeconomic drivers of house prices in Malaysia using vector error correction model over a fifteen year period 1999-2013. Pillaiyan (2015) study found that stock market was positively related to the Malaysian housing prices i.e. stock market price was a long term driver of house prices suggesting that profits gained from investments in stocks are reinvested in residential properties in line with the wealth effect.

Fry, Martin, and Voukelatos (2010) undertook a structural vector autoregression model to identify overvaluation in house prices in Australia from 2002 to 2008. They observed that evidence of overvaluation in real house prices, reaching a pick of 15 per cent. Factors that drove the overvaluation were housing demand shocks, macroeconomic shocks and wealth effects from equity market. There observed that increase in stock values flow through to higher property prices, suggesting that house prices is complicated by wealth effect.

Miregi and Obere (2014) carried out a study on the effects of market fundamental variables on property prices in Kenya, a case of Nairobi from year 2001 to 2013. The study took an explanatory design that aimed to establish the importance of the variables on interest in the determination of property prices. As per the study findings there was no relationship between property and stock market price, despite huge theoretical and empirical evidences 
linking stock as an alternative investment to real estate. To this effect Miregi and Obere (2014) recommended further investigation into the relationship between real estate and stock markets in Kenya.

Goodness et al. (2011) employed non-parametric approach in South Africa and observed that the housing market and stock market were correlated in the short run and long run i.e. instability in either of the markets could spill over to the other market. Goodness et al. (2011) observed that there is a wealth effect and credit-price effect inter-dependence between the stock market and housing market in South African economy.

Apergis and Lambrinidis (2011) explored the relationship between the stock market and the real estate market. The methodologies of co-integration and error correction modelling along with data from both the US and the UK stock and real estate markets over the period 1985-2006 were used. In particular, it has attempted to investigate whether stock markets and real estate markets are integrated or segmented. The results displayed that the two markets are rather integrated, with the relationship increasing when the securitized real estate markets are considered.

Previous literature gives huge disparity in the size and direction of the effect of stock market price to performance of residential property market performance. In some studies, stock market price was found to have a positive effect in support with the wealth effect (Pillaiyan, 2015; Fry, Martin, \& Voukelatos, 2010; Goodness et al., 2011), while in others stock market price was found to have a negative effect in support to the substitution effect (Wokker \& Swieringa, 2016; Glindro et al., 2011), while yet in other stock market price effect was negligible toward the performance of residential property market (Miregi \& Obere, 2014). Based on the above confounding literature, this study aimed to test the following hypothesis: $\mathrm{H}_{0}$ : Stock market price has no significant effect on the performance of the residential property market in Kenya.

\section{Methodology}

This study adopted a positivist philosophical attitude using causal research design. The target population for this study was composed of 56 market quarter observations from 2005 to 2018 of the Nairobi Securities Exchange 20 share index and quarterly house price index of residential property market for secondary data. Kothari (2004) argue that secondary data means data that are already available. Census was employed in collecting the data of the market quarterly observations for the entire period as the sampling technique. Pandey and Pandey (2015), notes that a research should identify schedules and procedures to be used for acquiring the data and recording it accurately. A data collection sheet was therefore used to organize the data that was collected. This data was authentic and reliable since it was secondary data that was collected by credible agents and published reports. The research used Eviews econometrics software for analysis of the data.

According to Gujarati and Porter (2009) descriptive statistics consist of methods for organizing, displaying, and describing data by using tables and summary measurers. Descriptive statistics was presented to show the normality of the data. The tests employed included estimation of mean, medium, maximum, minimum, skewness, kurtosis and Jarque-Bera. The study purposed to check on serial correlation so as to avoid having a conclusion that may be misleading (Akter, 2014). The study also aimed to test for heteroskedasticity to ensure that the model that will be used does not loss its efficiency (Breusch \& Pagan, 1979). So as to arrive at conclusive inferences, the study employed t-statistics and the p-value to test the significance of the null-hypothesis for any type of hypothesis test (Kumar, 2014). Five per cent level of significance was compared with the p-value and significance of the predictor variable(s) concluded if the latter is less than five per cent (Filho et al., 2013). P-value is the exact lowest probability of rejecting the null hypothesis when it is true (Gujarati \& Porter, 2009).

Vector error correction model (short-run) and auto-regressive distributed lag (long-run) model were employed to test the hypothesis. According to Baum (2013) VECM are employed when the time series appear to be firstdifference stationary with their levels exhibiting unit root or nonstationary behaviour. Conventional regression estimators, including VARs, have good properties when applied to covariance-stationary time series, but encounter difficulties when applied to nonstationary or integrated processes. Baum (2013) further states that the VECM has an advantage as the resulting VAR from VECM representation has more efficient coefficient estimates. Further, according to Tserkezos (2013) it has a better interpretation of short run relationship between variables that have a co-integration relationship thus VECM was employed to measure the short-run relationship of the series under study.

Autoregressive distributed lag (ARDL) model was employed to measure long run relationship of stock market price and performance of residential property market in Kenya. According to Nkoro and Uko (2016) ARDL cointegration technique does not require pretest unlike other techniques. Thus ARDL co-integration technique is preferable when dealing with variables that are integrated of different order or combination of both. ARDL cointegration technique is robust when there is a single long-run relationship between the underlying variables in a small sample size ( 30 observations to 80 observations). The long run relationship of the underlying variables is detected through the F-statistic (Wald test) i.e. when the F-statistic exceeds the critical value band. The major advantage of the ARDL co-integration technique, as explained by Nkoro and Uko (2016) lies in its identification of the co-integrating vectors where there are multiple co-integrating vectors. The ARDL approach has the 
additional advantage of yielding consistent estimates of the long-run coefficients that are asymptotically normal, thus ARDL was employed to test the long run relationship of the variables under study.

\section{Results}

Table 1 presents secondary descriptive statistics for the variables under study. Table 1: Summary statistics for the secondary data set

\begin{tabular}{lcc}
\hline & RPM & SMP \\
Mean & 1.18 & 8.29 \\
Median & 1.25 & 8.29 \\
Maximum & 5.10 & 8.61 \\
Minimum & -3.10 & 7.89 \\
Std. Dev. & 2.13 & 0.20 \\
Skewness & -0.09 & -0.21 \\
Kurtosis & 2.23 & 1.96 \\
Jarque-Bera & 1.48 & 2.93 \\
Probability & 0.47 & 0.23 \\
Observations & 56 & 56 \\
\hline
\end{tabular}

Residential property market performance (RPM) was measured by the percentage change in quarterly house price index. The positive mean of 1.18 shows that on average there was an increase in residential property market prices by 1.18 per cent over and above the previous quarter price. The standard deviation of 2.13 indicates that even though there was a noticeable increase in residential property prices over time, the fluctuations in percentage change between one period and another were considerable. Residential property market performance portrays a negative skewness -0.09 indicating a left tail of distribution that is approximately symmetric (Brown, 2011). Kurtosis value was 2.23 which is less than 3 , which shows that the variable is platykurtic. The platkurtic observation of residential property market performance shows that this market was considered less risky than would be a normal market in Kenya. This series had a Jarque-Bera value of 1.48 and its p-value of 0.47 shows that the residential property market performance had no significant departure from normality.

Stock market price (SMP) was measured by the natural log of quarterly Nairobi Securities Exchange 20 share index. The positive stock market price mean of 8.29 is similar to its median of 8.29. The standard deviation of 0.20 is associated with volatility of the series which is relatively small when compared with the series data. This implies that there are less likely unpredictable deviations in the series. The gap between maximum and minimum value (Maximum; 8.61, Minimum; 7.89) of stock market price indicates that there was a considerable difference between low and high stock values. Stock market price portray a negative skewness -0.21 indicating a left tail of distribution which indicates that the variable is approximately symmetric (Brown, 2011). Kurtosis value was 1.96 which is less than the value of 3 , which shows that the variable is platykurtic. Applying the Ivanoski, Stojanovski, and Narasanov (2015) discussion on Kurtosis the stock market has less random or unpredictable events that would influence its price than would be a normal market. Furthermore, Jarque-Bera value of 2.93 and a p-value of 0.23 shows that the variable had no significant departure from normality (Dettling, 2017).

Table 2: VEC residual serial correlation LM tests of stock market price and residential property market performance in Kenya

VEC Residual Serial Correlation LM Tests, Null Hypothesis: no serial correlation at lag order h, Sample: 2005Q1 2018Q4, Included observations: 52

$\begin{array}{ccc}\text { Lags } & \text { LM-Stat } & \text { Prob } \\ 1 & 1.421749 & 0.8404 \\ 2 & 2.598402 & 0.6271 \\ 3 & 2.548971 & 0.6359 \\ 4 & 2.315501 & 0.6779\end{array}$

Probs from chi-square with $4 \mathrm{df}$.

Table 2 presents the results for the test of serial correlation. The test results rejected the hypothesis of serial correlation in the model. The null was not rejected on the basis that the p-value of the chi-square (langragemultiplier-LM) was statistically insignificant for all the four quarters. In particular for lag one the LM-statistic was 1.421749 and $p$-value was 0.8404 . This shows that there was no serial correlation at lag one since the p-value was above 0.05 level of significance. The same was observed for lags two to four where their $\mathrm{p}$-values were above the 0.05 level of significance. This implied absence of serial correlation for the time series with four lags. 
Table 3: VEC residual heteroskedasticity test of stock market price and residential property market performance in Kenya

VEC Residual Heteroskedasticity Tests: No cross terms (only levels and squares)

Sample: 2005Q1 2018Q4, Included observations: 52

Joint test:

Chi-sq. $\quad$ df Prob.

$38.59144 \quad 42 \quad 0.6214$

Individual components:

$\begin{array}{lcllll}\text { Dependent } & \text { R-squared } & \mathrm{F}(14,37) & \text { Prob. } & \text { Chi-sq.(14) } & \text { Prob. } \\ \text { res1*res1 } & 0.31772 & 1.230707 & 0.2957 & 16.52142 & 0.2826 \\ \text { res2*res2 } & 0.26462 & 0.951013 & 0.5177 & 13.76029 & 0.4677 \\ \text { res2*res1 } & 0.20181 & 0.668214 & 0.7890 & 10.49423 & 0.7252\end{array}$

Table 3 presents the result of residual heteroskedasticity test. From the above results the presence of heteroskedasticity was rejected since the p-values for the joint test were statistically insignificant. In the individual components the presence of heteroskedasticity was also rejected.

Table 4: VECM result of stock market price and residential property market performance in Kenya (Short run)

$\begin{array}{cc}\text { Cointegrating Eq: } & \text { CointEq1 } \\ \text { RPM(-1) } & 1.000000 \\ \text { SMP(-1) } & -0.173183 \\ & (0.02491) \\ & {[-6.95175]} \\ \text { Error Correction: } & \mathrm{D}(\mathrm{RPM}) \\ \text { CointEq1 } & -0.657362 \\ & (0.21628) \\ & {[-3.03942]} \\ \text { R-squared } & 0.398602 \\ \text { Adj. R-squared } & 0.318416 \\ \text { F-statistic } & 4.970947 \\ \text { Log likelihood } & -98.53221 \\ \text { Akaike AIC } & 4.058931 \\ \text { Schwarz SC } & 4.321599\end{array}$

Table 4 presents the vector error correction model results used to measure the short run effect of stock market price on the performance of residential property market in Kenya. From the findings it can be observed that in the short run stock market price had a negative effect on performance of residential property market in Kenya. The regression coefficient of stock market price had an associated t-statistic value of -6.95175 which was statistically significant. From the r-squared it can be observed that variations in stock market price could explain up to 39.8602 per cent of performance of residential property market in Kenya. The F-statistic of 4.970947 implies that the model was significant. The result also shows the error correction term value of -0.657362 . This value shows the speed of adjustment toward equilibrium value was $65.7362 \%$. The associated t- statistic value of -3.03942 was statistically significant. The results show negative effect between stock market price and residential property market performance in the short run.

In the short run, the results of this study were in line with the substitution effect i.e. investors will prefer to invest in markets with better returns over markets with lower returns. Similar results were observed by Glindro et al. (2011) who investigated the characteristics of house price dynamics and the role of institutional factor in nine Asia-Pacific economies during 1993-2006. Glindro et al. (2011) observed that equity prices are negatively related to house prices, suggesting that the substitution effect dominates the wealth effect.

Wokker and Swieringa (2016) also observed negative relationship between stock market price and house prices. According to Wokker and Swieringa (2016) investors use past performance as an indicator of an asset class's future performance then a fall in stock returns would decrease expected future returns and thereby reduce the attractiveness of stocks in comparison to residential property market. This would imply a negative correlation between stock market and property market performance in support of the substitution effect.

This study finding differed with Fry, Martin, and Voukelatos (2010) study that undertook a structural vector autoregression model to identify overvaluation in house prices in Australia from 2002 to 2008. Fry, Martin, and Voukelatos (2010) observed that increase in stock values flow through to higher property prices, suggesting that house prices is complicated by wealth effect. Pillaiyan (2015) had the same findings as Fry, Martin, and Voukelatos (2010) with regard to stock market price effect on house prices.

Apergis and Lambrinidis (2011) explored the relationship between the stock market and the real estate market. Apergis and Lambrinidis (2011) results displayed that the two markets are rather integrated, with the relationship increasing when the securitized real estate markets are considered in support of the wealth effect. 
The finding of this study also differed with Miregi and Obere (2014) study that carried out an investigation on the effects of market fundamental variables on property prices in Kenya, a case of Nairobi from year 2001 to 2013. Miregi and Obere (2014) study took an explanatory design that aimed to establish the importance of the variables on interest in the determination of property prices. As per Miregi and Obere (2014) study findings there was no relationship between property and stock prices.

The rationale of this result in the Kenyan setup was that in the short run investors will prefer a market with better returns thus they will chose whether to invest in stock market or residential property market based on the expected returns that yield more than the other. It is also good to note that in the short run finances are more limited hence the urge to invest in markets that will lead to higher yields.

Table 5: ARDL long run form result of stock market price against residential property market performance ARDL Cointegrating And Long Run Form: Dependent Variable: RPM: Dynamic regressors (4 lags, automatic), SMP: 2006Q1 2018Q4 : Included observations: 52 after adjustments: Maximum dependent lags: 4(Automatic selection): Model selection method: Akaike info criterion (AIC): Selected Model: ARDL(4,1)

Long Run Coefficients

Variable
SMP
SMP

$$
\text { Coefficient }
$$

4.989473

R-squared

Adjusted R-squared

S.E. of regression

Sum squared resid

Log likelihood

Durbin-Watson stat
0.171607

\section{Std. Error}

0.032900

0.973107

0.396179

0.330546

1.671028

128.4474

$-97.29597$

1.909976

Mean dependent var

S.D. dependent var

Akaike info criterion

Schwarz criterion

$\begin{array}{rc}\text { t-Statistic } & \text { Prob. } \\ 5.216105 & 0.0000 \\ 5.127365 & 0.0000 \\ & 1.375192 \\ & 2.042317 \\ & 3.972922 \\ & 4.198065 \\ & 4.059236\end{array}$

Prob.

Hannan-Quinn criter.

Cointeq $=$ RPM $-(0.171607 *$ SMP $)$

Table 5 presents the results of autoregressive distributed lag (ARDL) model that was employed to measure the effect of stock market price on the performance of residential property market in Kenya in the long run. From the results it can be observed that in the long run stock market price has a positive effect on the performance of residential property market in Kenya. The regression coefficient of stock market price value had an associated tstatistic value of 5.216105 which was statistically significant since the associated probability value was 0.000 . From the r-squared it can be observed that variations in stock market price could explain up to 39.6179 per cent of the performance of residential property market. Durbin-Watson statistics of 1.909976 shows absence of firstorder serial correlation in the error terms.

From the study findings it can be observed that in the long run the wealth effect takes precedence in explaining the effect of stock market price on the performance of residential property market in Kenya over the substitution effect that was observed in the short run. This study result concurred with Fry, Martin, and Voukelatos (2010), Pillaiyan (2015), and Apergis and Lambrinidis (2011) where they found out that stock market price and residential property market performance were integrated with the relationship increasing with increase in stock market price. The result finding differed with Wokker and Swieringa (2016) and Glindro et al. (2011) who found that this stock market price had a negative effect on property market.

The rationale of this finding in the Kenyan context was that in the long run a good performance in the stock market is an indicator that business are doing well and this good performance spills over to the residential property market where investors diversify their investments and the inverse is also true. This shows that in the long run investors feel more financially secure and confident about their wealth when their investment portfolios increase in value. This wealth effect reflects their psychological effect and encourages them to invest in other ventures particularly residential property market thus creating positive symmetric relationship between the markets.

\section{Conclusion}

The research set to investigate effect of stock market price on the performance of the residential property market in Kenya. The descriptive statistics were used to determine whether the series (stock market price and performance of residential property market in Kenya) were normally distributed. The results showed that the variables were slightly skewed. The kurtosis results also showed that the normality assumption was slightly violated. The JarqueBera test indicated that the variables had no significant departure from normality.

Review of stock market price effect on residential property market performance in the short run specific model revealed that stock market price had a negative effect on performance of residential property market in Kenya in support to the substitution effect. Under the long run overall model stock market price had a positive effect on the performance of residential property market in Kenya in support to the wealth effect.

The study concludes that stock market price had an explanatory power on performance of the residential property market in Kenya. This shows that in the long run investors feel more financially secure and confident about their wealth when their investment portfolios increase in value. This wealth effect reflects their psychological 
effect and encourages them to invest in other ventures particularly residential property market thus creating positive symmetric relationship between the markets. Nevertheless in the short run when investors are managing their investment portfolios the stock market investment opportunities will compete with residential property market opportunities based on their current performance in agreement with substitution effect leading to an inverse relationship.

The study recommends that residential property market investors in Kenya consider information from the stock market as it influences performance of the residential property market both in the long run and short run. Investors who are also strategizing on their investment portfolios should take into consideration the relationship between these two markets.

\section{References}

Akter, J. (2014). Bootstrapped durbin-watson test of autocorrelation for small samples. ABC Journal of Advanced Research, 3(2), 2304-2621.

Apergis, N. \& Lambrindis, L. (2011). More evidence on the relationship between the stock and real estate market. Journal of Economic Literature, 85, 2-18.

Baum, C. F. (2013). VARs, SVAR and VECM models. Boston: Boston College.

Breusch, S. \& Pagan, R. (1979). A simple test for heteroscedasticity and random coefficient variation. Econometrica, 47(5).

Brooks C. (2002). Introductory econometrics for finance: Cambridge University Press.

Brown, S. (2011, June). Measures of shape: skewness and kurtosis. Retrieved November 2018, from Tomkins Cortland Community College: http://www.tc3.edu/instruct/sbrown/stat/shape.htm

Creswell, W. (2013). Research design: Qualitative, quantitative, and mixed methods approaches. Sage Publications Ltd.

Dettling, M. (2017). Statistical analysis of financial data. Zurich: Swiss Federal Institute of Technology.

Engle, R. F. (1982). Autoregressive conditional heteroscedasticity with estimates of the variance of United Kingdom inflated. Econometrica, 50(4), 987-1008.

Filho, B., Paranhos, R., Rocha, C., Batista, M., Silva, A., Santos, W., et al. (2013). When is statistical significance not significant? Brazilian Political Science Review, 7(1), 31-55.

Fry, A., Martin, L. \& Voukelatos, N. (2010). Overvaluation in Australian housing and equity markets: Wealth effects or monetary policy? Economic Record, 86(275), 465-485.

Glindro, T., Subhanij, T., Szeto, J. \& Zhu, H. (2011). Determinants of house prices in nine Asia-Pacific economies. International Journal of Central Banking, 7(3), 163-203.

Goodness, A., \& Balcilar, M. \& Gupta, R. (2011). Long-and short-run relationships between house and stock prices in South Africa: A nonparametric approach. Working Papers 201136, University of Pretoria, Department of Economics.

Gujarati, N. \& Porter D. C. (2009). Basic econometrics (5th ed). New York: McGraw-Hill/Irwin inc.

Ivanoski, Z., Stojanovski, T. \& Narasanov, Z. (2015). Volatility and kurtosis of daily stock returns at MSE. UTMS Journal of Economics, 6(2) 209-221.

Jarque, C. M., \& Bera, A. K. (1987). A test for normality of observations and regression residuals. International Statistical Review, 163-172.

Kothari, R. (2004). Research methodology: Methods and techniques, (2nd ed.). Mumbai, India: New Age International (P) Limited, Publishers.

Kumar, R. (2014). Research methodology: A step-by-step guide for beginners. New Delhi, India: Sage Publications Ltd.

Miregi, O. \& Obere, A. (2014). Effects of market fundamental variables on property prices in Kenya - a case of Nairobi residential property market. Journal of Economics and Finance, 5(5), 101-113. www.iosrjournals.org.

Nkoro, E. \& Uko, K. (2016). Autoregressive distributed lag cointegration technique: application and interpretation. Journal of Statistical and Econometric Methods, 5(4) 63-91.

Pandey \& Pandey (2015). Research methodology: Tools and techniques. Romania, European Union: Bridge Centre Publishers.

Pillaiyan, S. (2015). Macroeconomic drivers of house prices in Malaysia. Canadian Social Science, 11(9), 119130. doi:10.3968/7482.

Reilly, K. \& Brown, C. (2012). Investment analysis and portfolio management (10th ed.). Mason, USA: SouthWestern Cengage Learning.

Tserkezos, D. (2013). Vector error correction models. Macedonia: University of Macedonia.

Wokker, C. \& Swieringa, J. (2016). Foreign investment and residential property price growth. Australia: The Australian Government the Treasury. 